\title{
Use of a Graded Approach in the Application of Management System Requirements for ETRR-2: Maintenance of the Standby Power Supply System as a Case Study
}

\author{
Ayman A. Eisa \\ Department of Nuclear Safety and Radiological Emergency, National Center for Radiation Research and Technology \\ Egyptian Atomic Energy Authority, Cairo, Egypt
}

\begin{tabular}{l} 
ART ICLE INFO \\
\hline Article history: \\
Received: $3^{\text {rd }}$ July 2020 \\
Accepted: $15^{\text {th }}$ July 2020 \\
\hline Keywords: \\
Integrated management \\
system, \\
Graded approach, \\
Maintenance Strategy, \\
Standby power supply \\
system.
\end{tabular}

1- INTRODUCTION

The Egyptian Atomic Energy Authority (EAEA) is a governmental research entity that owns the Egypt Second Research Reactor (ETRR-2). It is an open pool type, with a nominal power of $22 \mathrm{MW}$ and a maximum thermal neutron flux of $2.7 \times 10^{(14)} \mathrm{n} \mathrm{cm}^{-2} \mathrm{~s}^{-1}$. It is a multipurpose reactor used for research \& development in neutron physics, materials science, radioisotope production, neutron radiography, activation analysis, silicon-doping, beam tube applications, education and training in nuclear engineering and reactor operation [1]. A process for establishing an Integrated Management System (IMS) for the operation and maintenance phase of the ETRR-2 reactor is initiated. This process depends mainly on developing the existing quality assurance program to be an IMS following the requirements of the IAEA safety standards. The original quality program of the reactor was applied since its commissioning phase in accordance with IAEA Safety Series No. 50-C/SG-Q [2], which was valid at that time. The developed IMS considers international management standards [3-5]. By definition, the IMS is a single and coherent management system in which all the parts of an organization are integrated to enable achieving its objectives. The IMS was originated to integrate safety, health, environmental, security, quality and economic objectives and achieve their requirements [6]. It is realized that consideration of those requirements separately may introduce negative impact on safety. So, senior management realized the necessity to develop, implement and improve an IMS to ensure that safety is not compromised. The developed IMS takes into account the safety requirements for the ETRR-2, including the national regulatory requirements, conditions established by the reactor safety analysis report and operational limits and conditions, as well as the international safety requirements established by the IAEA up-to-date safety standards [7]. Also, many IAEA's guides [8-10] are utilized in the process of developing the IMS. 
The IAEA's approach to Management Systems has been improved throughout the years. Figure 1 presents the evolution of the IAEA approach to quality, leadership and management showing the organizational management system and detailed quality requirements levels during the last decades in order to achieve the highest level of safety and performance [11]. The main aim is to achieve and enhance safety by bringing together in a coherent manner all the requirements for managing the reactor; describing the actions necessary to provide confidence that all these requirements are satisfied; ensuring that health, environmental, security, quality and economic requirements are not considered separately from safety requirements, to help preclude their possible negative impact on safety. Safety is paramount within the management system, overriding all other demands, as stated in the IAEA safety standards [6].

Development and application of the IMS consider the use of a graded approach in order to commensurate the resources devoted to management system with the importance of an item/activity and the magnitude of the risks [8]. Of course, the safety requirements are applicable to all facilities and activities, and should be fulfilled. However, the way these requirements are met varies depending on the possible risk of the facility and the sophistication and nature of the activity. The graded approach will then be used to assess the most suitable way of implementing the technical and safety requirements to commit sufficient resources so that safety is not compromised in achieving the organization 's health, environmental, security and economic objectives. By conducting a brief historical review of the graded approach mentioned in the different IAEA's publications, it is obvious that the concept of grading was and still is a main requirement in the application of management system demands. Previous publications [2, 6 and7] reported that the management system shall be developed and applied using a graded approach. IAEA's general safety guides [8-9] have also referred to the graded approach. Many other specific publications are issued especially for explaining graded approach: the IAEA- TECDOC-1740 [12] reported many examples of methodologies for grading the application of management requirements and models, for previous experience in a wide range of installations, the grading of which are given in the Annexes of that report. A specific safety guide [13] was issued especially to tackle grading in research reactors. The IAEA Safety Report [10] also introduced an example of a graded approach to the application of management system requirements for a research reactor in Annex II. Lately, the IAEA has published the most recent document relate to QA and QC [11] which assigns section (3.7.) especially for grading.

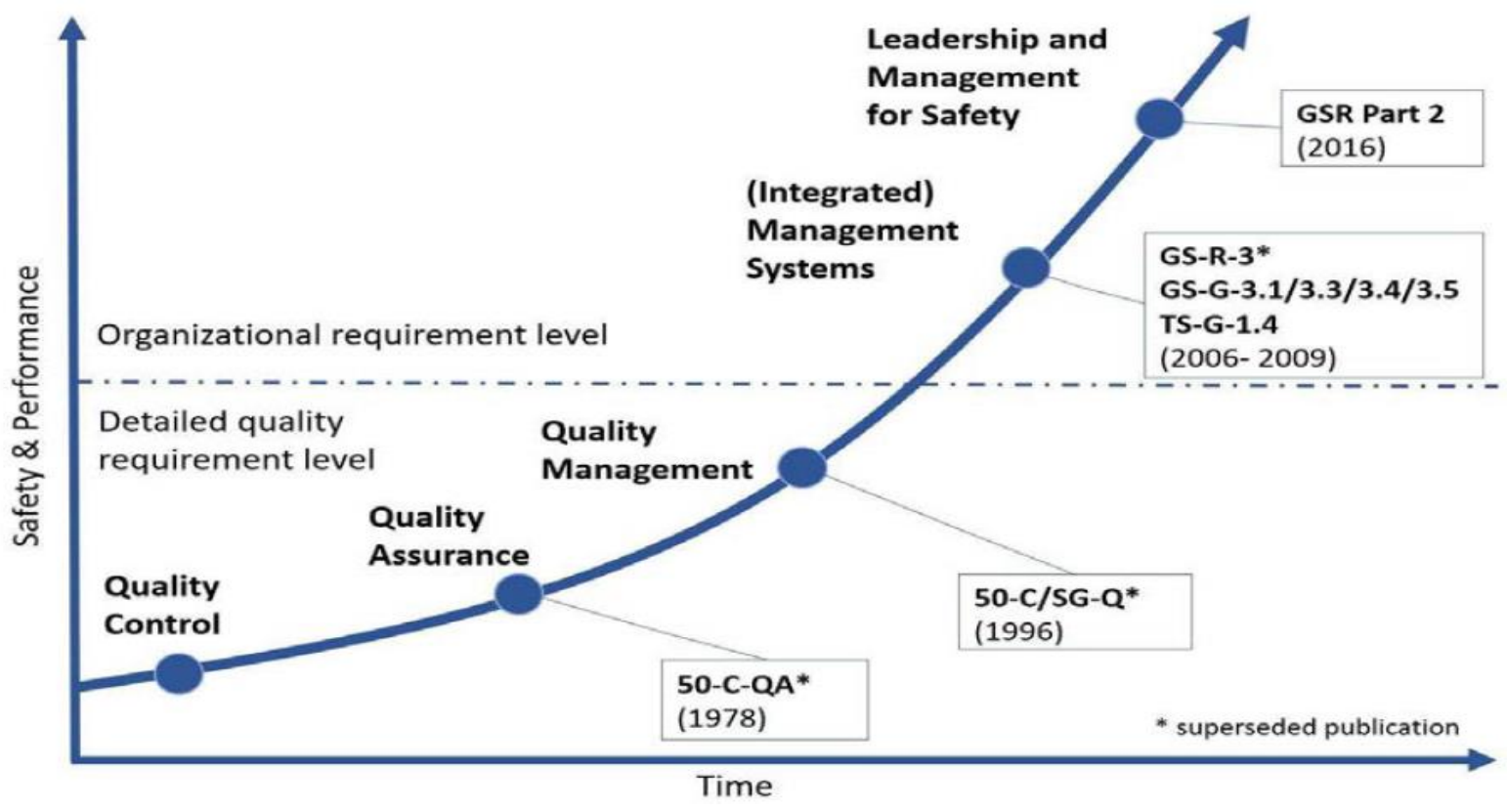

Fig. (1): Evolution of the IAEA approach to quality, leadership and management showing the organizational management system and detailed quality requirements levels [11]. 


\section{The IAEA Definition of a}

\section{Graded Approach}

The IAEA Safety Glossary [14] has given a general definition and purpose of the graded approach which are applicable to the safety requirements of the IAEA [1516]. The glossary stated this definition: [For a system of control, such as a regulatory system or a safety system, a process or method in which the stringency of the control measures and conditions to be applied is commensurate, to the extent practicable, with the likelihood and possible consequences of, and the level of risk associated with, a loss of control].

Extensive review of the literature shows that different methods were adopted to use a graded approach in the application of the safety and technical requirements [12]. Through this review, it is recognized that every situation is unique and that we must adapt the graded approach that best fits our circumstances. So, the present study provides an additional example for the methodology of applying such approach to the ETRR2. The goal of this study is to support the ETRR-2 management staff considering the adoption of the graded approach by citing a model, indicated in [12], of organizations with significant experience in efforts to improve the IMS. A grading methodology for items and activities included in the ETTR-2 is proposed in this study as follows; section 2 introduces description of the graded approach methodology and a proposal for classification of items or activities in the ETRR-2 into four categories. Section 3 gives a grading example of specific controls for maintenance of structures, systems and components (SSCs) in the plant and explains the management requirement appropriate for each grade. Finally, the application of the proposed methodology to the electrical Standby Power Supply (SPS) system, as a case study, is discussed in section 4 .

\section{2- USE OF A GRADED APPROACH}

The QA program of the ETRR2 reactor during its design, construction, installation and commissioning phases had a graded approach for the quality levels of products according to the methodology described on the project procedures. This approach has continually been used in the plant quality manual during the operation and maintenance phase [10]. During the process of developing IMS, it is thought that the grading methodology should also be improved in order to follow the up-to-date standards. According to the current standards, grading of the application of management system requirements is applied to the items and activities of each process, on the basis of the consideration of: the significance and complexity of each item or activity; the hazards and the magnitude of the potential impact (risks) associated with the safety, health, environmental, security, reliability and economic elements of each item or activity; and the possible consequences if inadequate (or loss of) control for an item/activity is occurred.

\section{Detailed steps for grading of an item or activity}

The IAEA TECDOC-1740 [12] provides guidance on, and examples of, a graded approach to the application of the management system requirements for facilities and activities. It explains the process to apply the grading methodology to an item/activity in details, and stated that the procedure should contain the following steps (see figure 2):

1. Identify the classification, if applicable

2. Assess the significance of the item/activity, using the criteria for grading, to identify a preliminary grade.

3. Consider other factors that may increase the preliminary grade level, such as

- External requirements: contract, code, regulation, standard

- Process and organizational interfaces

- Variability

- Novelty

- Uniqueness

- Performance history

- Operating experience

- Accessibility (e.g. for test, inspection, maintenance, during normal operation)

- Ability to prove functionality or reliability after installation.

4. Assign a grade.

- As appropriate, verify that the correct grade has been assigned.

5. Specify controls appropriate to the grade.

To establish the necessary grading of an item/activity, the responsible individual should be guided, through a series of questions directed to experts in different specialties, to enable him to determine the consequences if there is inadequate or loss of control (an item fails or an activity is carried out incorrectly). The information in this case may be obtained primarily through interviews with plant personnel, with additional information being 
provided by the ETRR-2 quality system in hard copy form. The management system defines applicable requirements for each grade. When developing the structured approach to grading, the level of detail at which requirements are applied to activities and/or SSCs is determined. The level of detail covers: the need for and strictness of the analysis to be conducted, the frequency of activities such as calibration, testing and preventive maintenance, the stringency of required approvals and the degree of oversights.

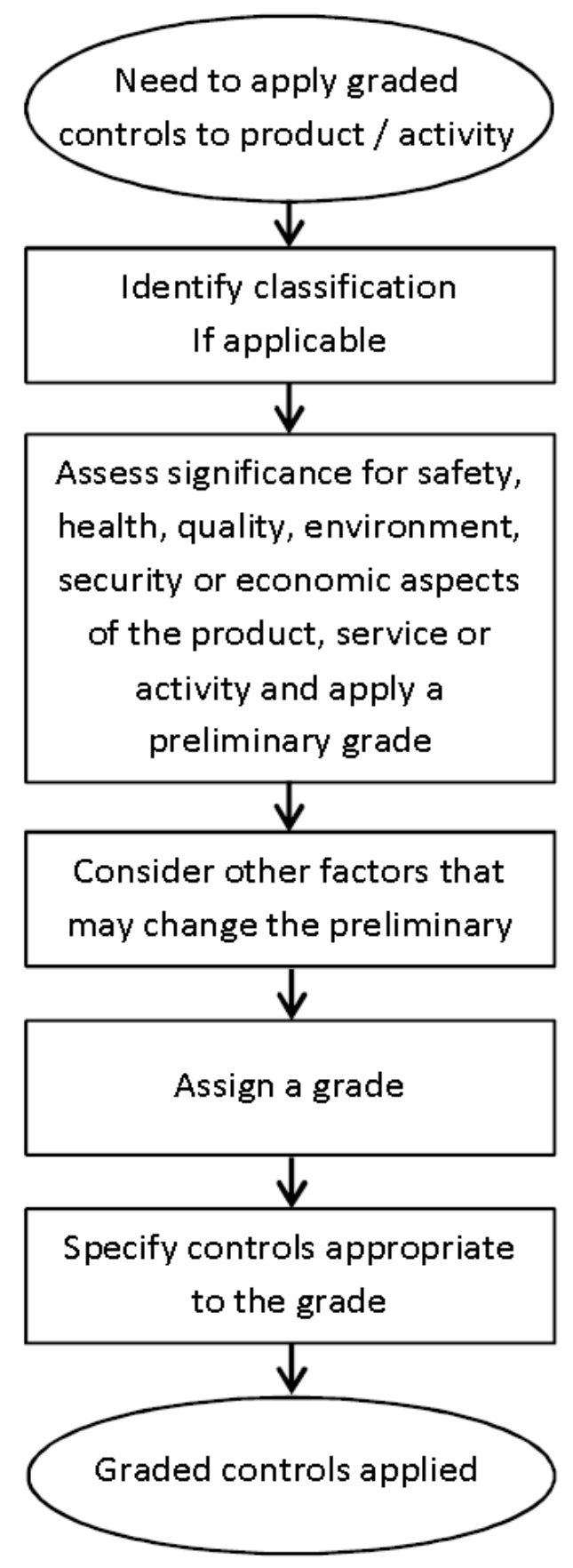

Fig. (2): The process for grading of an item or activity [12]

\section{Classification Formula}

The following formula, which is quoted in Annex IV of TECHDOC 1740, is proposed to determine the total rating of each item or activity and in turn gives its importance grade [12]:

Total grading score $=2 \mathrm{a}+\mathrm{b}+\mathrm{c}+\mathrm{d}+\mathrm{e}$

Where: $a, b, c, d, e$, and $f$ are different factors representing numerical significance to the following six parameters:

1. Safety (Factor a)

2. Reliability (Factor b)

3. Complexity (Factor c)

4. Environment (Factor d),

5. Health (Factor e)

The criteria applied to obtain the value for each factor is as follows:

\section{- Safety (a):}

This factor includes nuclear, radiation, physical, and the so called industrial safety. It has a weight of 2, to confirm that safety is paramount within the management system and overriding all other demands. Its value can range from 0 to 5 , where the item /activity failure or improper (or loss of) control consequences:

- $\quad$ not cause injury to the operating personnel $(a=0)$;

- could injure the operating personnel $(\mathrm{a}=1)$;

- could injure the operating personnel with serious injury $(\mathrm{a}=2)$

- could injure or kill the operating personnel and injure the general public $(\mathrm{a}=3)$;

- $\quad$ would injure or kill the operating personnel and injure the general public $(a=4)$;

- would injure or kill the general public and the operating personnel $(\mathrm{a}=5)$

\section{- Reliability (b):}

This factor includes considerations on the loss of profit, delay or interruption of operation and radioisotope production, failed repair work. Its value can go from 0 to 2 , where the item/activity failure or improper (or loss of) control consequences:

- causes slight inconveniences and/or expenses $(b=0)$.

- results in significant damage to the service of the plant and/or significant costs $(b=1)$.

- results in the total loss of the service of the plant and/or extremely serious costs $(b=2)$.

\section{- Complexity (c):}


This factor includes consideration of the design, difficulties in replacing parts, accessibility for maintenance and unique items or activities that additional controls are needed. Its value can go from 0 to 2 , where the (item or activity):

- is quite simple $(\mathrm{c}=0)$.

- has some difficult parts or characteristics that are strictly interrelated $(\mathrm{c}=1)$.

- has a large number of difficult parts or strictlyinterrelated characteristics $(\mathrm{c}=2)$.

\section{- Environment (d):}

This factor includes consideration of environmental regulations governing this item or activity that requires specific additional controls. Its value can go from 0 to 2 , where the item/activity failure, improper (or loss of) control consequences:

- has no environmental effect $(\mathrm{d}=0)$.

- could have significant effect on the environment $(\mathrm{d}=1)$.

- would have significant effect on the environment, where environmental damage could exceed regulatory limits or involve significant clean-up $\operatorname{costs}(\mathrm{d}=2)$.

\section{- Health (e):}

This factor includes consideration of health regulations governing this item or activity that requires specific additional controls. Its value can go from 0 to 2 , where the item/activity failure, improper (or loss of) control consequences:

- has no effect on the health of the operating personnel or the public $(\mathrm{e}=0)$.

- could have accumulated (long run) effect on the health of the operating personnel or the public $(\mathrm{c}=1)$.

- would have an immediate effect on the health of the operating personnel or the public $(\mathrm{c}=2)$.

Then the importance grade is obtained by applying the results of a classification formula in accordance to the following:

- Grade "1": when the total grading score is within the range from 15 to 20 and/or "a" $=4$ or 5 and/or "b" = 2

- Grade "2": when the total grading score is within the range from 10 to 14 and/or "a" $=3$ and/or "b" $=2$.

- Grade "3": when the total grading score is within the range from 5 to 9
- Grade "4": when the total grading score is within the range from 0 to 4

Where, grade "1" represents the most stringent level of requirements. It is clear that the first term of the equation will be $50 \%$ of the total points if the safety factor (a) has its maximum value (the most severe consequences). It is intended to have this weight in the equation to demonstrate the significance of safety and to prove its paramount importance above all other factors.

\section{3- EXAMPLE OF CONTROLS APPROPRIATE TO EACH GRADE}

The grading of specific requirements for maintenance of structures, systems and components (SSCs) for the plant is taken as an example in this study [17]. The maintenance staff comprises a big percentage of the total manpower of the plant and maintenance spending can be one of the largest parts of the operational budget. So, optimizing the fraction of employees working in the maintenance area, as well as the fraction of maintenance spending on the total operational costs, is an important target when improving a maintenance management system. Grading approach is an essential step in improving maintenance management, as it makes the resources devoted to maintenance management commensurate with the importance of the SSC so as to deploy appropriate resources [18].

As well known, proper maintenance should be performed to ensure that equipment reach or exceed its design life to secure the maximum return on the investment that they represent. Hence, it is very important to determine the equipment grade and apply the proper management requirements (controls) of the maintenance process for each grade. In other words, the most suitable maintenance strategy is applied for each structure, system or component (SSC) according to its grade. For example, the maintenance regimes can be selected to be appropriate for the four grades according to the four famous maintenance generations [19-20]. These generations evolved in its strategy from reactive one (fix the broken items) to an asset management system that has plans in place to ensure maintenance of the most critical (grade 1) SSC is kept up to date [21]. One of the proven modern techniques for maintenance is the reliability centered maintenance (RCM), which is a method for determining the most appropriate policy for any given asset in its present operating context [22]. In this way, the classification of the maintenance process can be as follows: 
1. Maintenance for SSC grade 1: a proactive maintenance, which is characterized by focusing on failure elimination where the SSC is always in working order and under continuous surveillance and in-service inspection programs.

2. Maintenance for SSC grade 2: Predictive maintenance, which is characterized by focusing on predicting, preventing and avoiding the consequences of equipment failure where limited unavailability of the SSC is allowed.

3. Maintenance for SSC grade 3: Preventive maintenance, which is characterized by focusing on improving maintenance planning and scheduling where economically reasonable maintenance is allowed.

4. Maintenance for SSC grade 4: Corrective maintenance, which is characterized by focusing on repair tasks where normal operation supervision is enough.

The following Table shows some examples of the controls that should be applied for each grade.

Table (1): Example for some of the controls on maintenance process applied for each grade

\begin{tabular}{|c|c|c|c|c|}
\hline Control & Grade 1 & Grade 2 & Grade 3 & Grade 4 \\
\hline \multicolumn{5}{|l|}{$\begin{array}{l}\text { Maintenance } \\
\text { Strategy }\end{array}$} \\
\hline Tactic & $\begin{array}{l}\text { Proactive, } \\
\text { Reliance }\end{array}$ & Predictive & Preventive & $\begin{array}{c}\text { Reactive, breakdown } \\
\text { (corrective) }\end{array}$ \\
\hline Failure management & $\begin{array}{l}\text { Self-analysis, failure } \\
\text { elimination }\end{array}$ & $\begin{array}{l}\text { historical Failure } \\
\text { mode, critical data } \\
\text { analysis }\end{array}$ & $\begin{array}{l}\text { Periodic maint., } \\
\text { Scheduled overhaul }\end{array}$ & Operate to failure \\
\hline Measures & Probabilities & $\begin{array}{l}\text { Equipment } \\
\text { effectiveness }\end{array}$ & Availability & Throughput \\
\hline \multicolumn{5}{|l|}{$\begin{array}{c}\text { Work/Process } \\
\text { Control }\end{array}$} \\
\hline Authorization & Regulatory body & Safety committee & Reactor manger & Maintenance head \\
\hline \multicolumn{5}{|l|}{$\begin{array}{l}\text { Documented } \\
\text { information }\end{array}$} \\
\hline Reviewer & Reactor manager & Maintenance head & Process owner & Authorized person \\
\hline Approver & Top manager & Reactor manager & Maintenance head & Process owner \\
\hline Softcopy Storage & Standalone machine & Machine in the plant & Machine in the plant & $\begin{array}{l}\text { Any machine or } \\
\text { removable device }\end{array}$ \\
\hline Hardcopy Storage & $\begin{array}{l}\text { secure \& approved } \\
\text { vault with access } \\
\text { control }\end{array}$ & $\begin{array}{l}\text { approved place with } \\
\text { assigned key holder }\end{array}$ & Locked drawer & Local drawer \\
\hline $\begin{array}{l}\text { Records retention } \\
\text { time }\end{array}$ & $\begin{array}{c}\text { Plant lifetime } \\
\text { (important for } \\
\text { decommissioning) }\end{array}$ & 10 years & 5 years & 1 year \\
\hline \multicolumn{5}{|l|}{ Personnel } \\
\hline Qualification & Outsourced expert & Expert & Senior & Junior \\
\hline Training & $\begin{array}{l}\text { Documented specific } \\
\text { training }\end{array}$ & Certification & Qualification & Awareness \\
\hline $\begin{array}{l}\text { independent } \\
\text { monitoring }\end{array}$ & $\begin{array}{l}\text { QA officer full } \\
\text { review }\end{array}$ & $\begin{array}{l}\text { QA officer full } \\
\text { review }\end{array}$ & $\begin{array}{c}\text { Limited on-site } \\
\text { reviews }\end{array}$ & Not required \\
\hline
\end{tabular}




\section{4- APPLICATION OF THE METHODOLGY ON THE ETRR-2 STANDBY POWER SUPPLY SYSTEM}

The electric power supply system of the nuclear installation is one of the most important systems from the safety point of view. It is necessary to provide sufficient power of suitable quality to other systems and equipment to ensure their capability to perform their safety functions when required. Particularly for reactors, the availability of reliable electrical power supplies for essential functions in DBAs "design basis accidents" should be included in the design basis of the electrical power system [16]. Generally, the structures, systems and components (SSCs) used for the operation of a nuclear reactor is classified from the nuclear safety point of view. According to these considerations, the electric loads in the ETRR-2 have been classified into the following categories:

\section{- Class "A":}

Loads that do not tolerate loss of electric power at all are essential to the operation, safe shutdown, or isolation of the plant and whose failure can result in the release of radioactive material. Equipment performing data processing which require a power supply that is theoretically conditioned, i.e., uninterruptible and free of voltage and frequency excursions are good example of class A loads.

\section{- Class "B":}

Loads that tolerate loss of electric power for a certain period of time are essential to the operation, but are not essential for safe shutdown, or isolation of the plants and whose failure cannot result in the release of radioactive material. The maximum period for the interruption of electrical power supplies is specified in this case. Emergency exit lighting and some other types of life safety-related loads require restoration of power after an outage in no more than a few seconds are examples of class B loads.

\section{- Class " $\mathrm{C}$ ":}

Loads that tolerate loss of electric power for an undetermined (indefinite) period of time are not essential to the operation, safe shutdown, or isolation of the plants and whose failure cannot result in the release of radioactive material.

\section{General description of the ETRR-2 Electric Power Supply system}

One of the IEEE standard typical configurations, which is called secondary selective system, is used in the radial feeding of electricity for the ETRR-2 [23]. As shown in figure 3, the ETRR-2 electrical power system is supplied by two independent sources at medium voltage level to keep good reliability. Each source feeds a separate transformer through a circuit breaker. It is very important to provide sufficient power of suitable quality to systems and equipment to ensure their capability to perform their safety functions when required. The electrical system is designed to meet demands for startup, normal operation and shut-down conditions. Extra circuit reliability is provided for critical loads which are important to safety (Class "B" and Class "A" loads). The electric power system is designed to provide a simple bus arrangement for easiness and safety in switching operations, allowing considerable operating flexibility. 


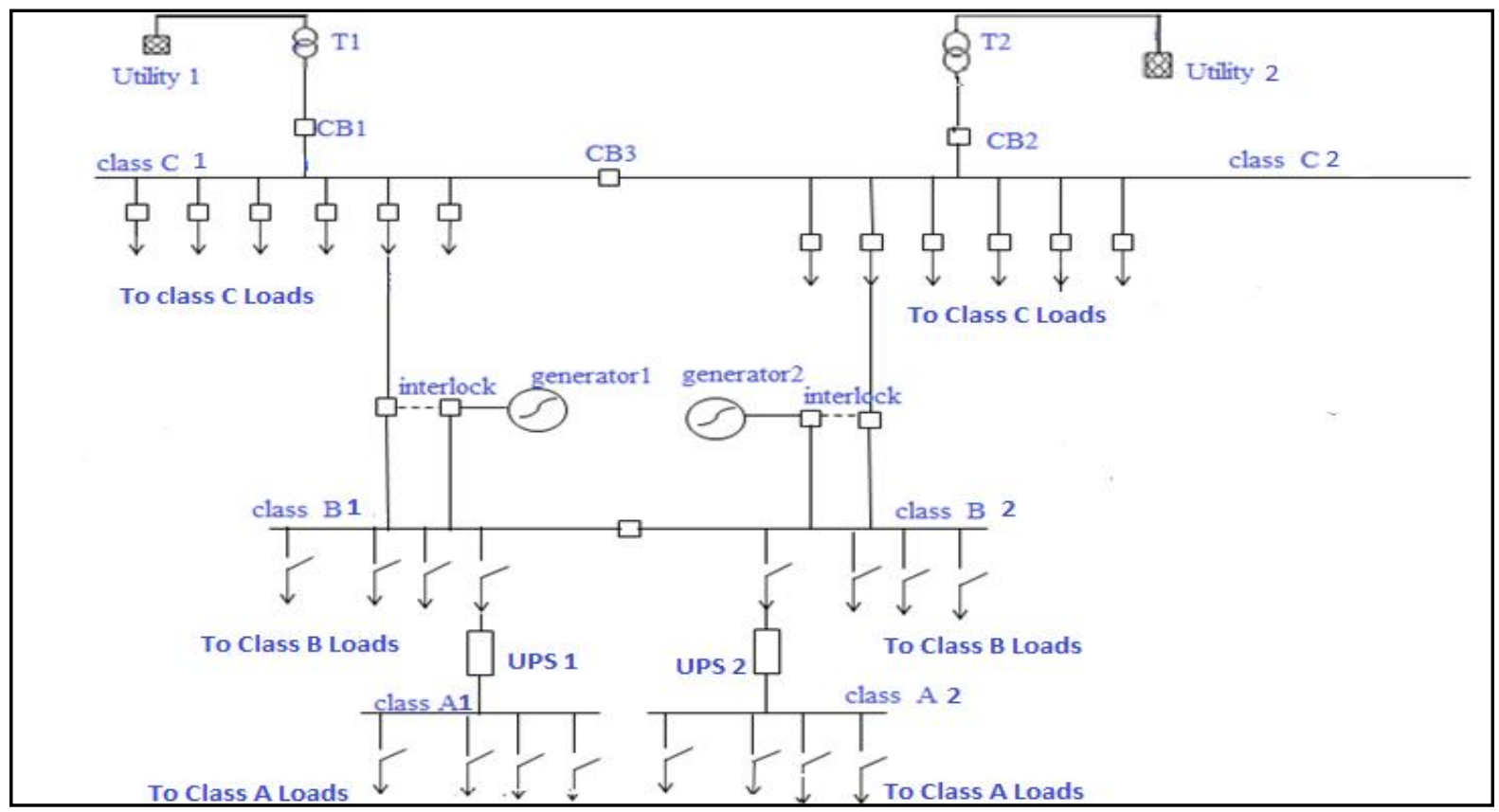

Fig. (3): Sources of electric power and load classes for ETRR-2

\section{Power supplies types}

In view of increasing the reliability and availability of the system, electric power is supplied as from different sources, which are undependable. Independence of components and circuits can be achieved by physical separation or electrical isolation, so that any single failure affects only one source of supply and does not propagate to other sources [24]. Specifically, electric power supplies are divided into three types, which are important in the defence in depth concept [25]:

- Main (preferred) power supply: Utility $11 \mathrm{kV}$ lines (off-site). Feed power all the time to start-up the plant and manage the electricity demand as a whole.

- Standby AC power supply: two Standby Diesel Generator sets (on-site). Feed essential plant's services during a main power cut-off.

- Uninterruptible Power Supply: Uninterruptible Power Systems UPSs (on-site and near to the supplied load). Feed power to loads of relevant equipment without interruption in time from the cutoff of the main source until the connection of the standby power source.

In case of supply interruption from the external lines (preferred power supply) and until the onsite power plant (standby AC power supply) starts supplying energy, electrical loads requiring uninterruptible power (i.e., class A loads) are fed from an uninterruptible power supply.

\section{Description of the SPS system}

The Standby Power Supply (SPS) system of the ETRR-2 is designed to withstand seismic events, hurricanes and other external events considered in the design basis of the plant and it is classified as safety grade. Also, the starting load requirements of the various items of equipment served by the system are taken into account. It is considered to ensure the availability of emergency electrical power when it is required for systems important to safety [26]. The following are detailed description of the installed SPS system:

- Two identical diesel generators (DG1 and DG2) are placed in the Diesel Generators Room (DG room), which is located in the ETRR-2 site. They meet the simultaneous demand of Class "B" loads in ETRR2. The DG room is located at an independent area from ETRR-2 reactor building to increase the security.

-Class B electric loads supplied by the SPS is subdivided into two main distribution systems to feed class "B" loads in the Left bus, and class "B" loads in the Right bus. Each distribution system has sufficient capability to supply its connected loads in case the external $11 \mathrm{kV}$ lines are unavailable. Each diesel generator supplies one train (G1 feeds the Left buses and G2 feeds the right buses) by means of physically separated underground radial feeders (see figure 3). There is no parallel operation of the SPS with the normal power supply neither between the two diesel generators. 
-Loss of voltage or degradation of the normal power supply is sensed and used to send a starting signal for the corresponding DG.

As a case study, the proposed methodology for grading is applied to the SPS system. In order to determine the grade of this system, the above mentioned qualification formula in equation (1) was used. Determining the value of each factor requires experts in miscellaneous fields in order to assign the right value depending on analytical studies that conclude the possible consequences if the SPS system fails or its maintenance program is carried out incorrectly. The results are as follows:

- Safety (a): Safety experts gave this factor the value 3. Accordingly, the SPS system can be considered directly to have grade 2 . However, the other factors are determined in order to be sure that this resulted grade level is right.

\section{5- SUMMERY AND CONCLUSION}

Many publications have introduced different methods for the concept of the graded approach which is very important in applying the management, safety and technical requirements. This study provides an additional example of such approach for classification of items or activities in the ETRR-2 into four grades. It proposes a formula to determine the total score of each item or activity, which includes different factors representing numerical significance to the considerations that need to be taken into account in grading the application of integrated management system (IMS) requirements. The importance grade is obtained by applying the results of this classification formula. Then, the paper gives an example of specific controls for maintenance of structures, systems and components (SSCs) in the plant and explains the management requirements appropriate for each grade. Finally, it discusses the application of the proposed methodology in the electrical Standby Power Supply (SPS) system as a case study. The author anticipates that this proposed method is more attractive since it combines all the divisions of IMS in one simple approach.

\section{6- REFERENCES}

[1] M.K. SHAAT, Utilization of ETRR-2 and Collaboration, Technical Meeting on Commercial Products and Services of Research Reactors, 28 June-2 July, 2010, IAEA, Vienna IAEA-TM-38728 (2010)
- Reliability (b): Senior managers gave this factor the value 1 .

- Complexity (c): Maintenance head gave this factor the value 1 .

- Environment (d): Environmental experts gave this factor the value 1 .

- Health (e): The physicians gave this factor the value 1 .

- Security (f): Security experts gave this factor the value 1 .

In this case, the total points will be 11 and the factor a (safety) is 3. So, the grade level of this system is grade 2 . Hence, the predictive maintenance tactics should be applied to the SPS system and the management requirements for this system are as indicated in the second column in Table (1) considering the fundamentals of electrical safety and maintenance testing of electric power systems [27].

[2] Quality Assurance for Safety in Nuclear Power Plants and other Nuclear Installations, IAEA Safety Series No. 50-C/SG-Q, IAEA, Vienna (1996).

[3] ISO 9001-2015, Quality Management System: Requirements, the International Organization for Standardization

[4] ISO 14001- 2015, Environmental Management System: Requirements with guidance for use, the International Organization for Standardization

[5] OHSAS 18001:2007 OCCUPATIONAL HEALTH AND SAFETY ASSESSMENT SERIES, Occupational Health and Safety Management System: Requirements

[6] The Management System for Facilities and Activities, IAEA Safety Standards Series No. GS-R3, Vienna, 2006.

[7] Leadership and Management for safety, IAEA Safety Standards Series No. GSR Part2, Vienna (2016)

[8] Application of the Management System for Facilities and Activities, IAEA Safety Standards Series No. GS-G-3.1, IAEA, Vienna (2006).

[9] The Management System for Nuclear Installations, IAEA Safety Standards Series No. GS-G-3.5, IAEA, Vienna (2009).

[10] Implementation of a Management System for Operating Organizations of Research Reactors, SAFETY REPORTS Series No. 75, IAEA, Vienna (2013). 
[11] Quality Assurance and Quality Control in Nuclear Facilities and Activities Good Practices and Lessons Learned. IAEA-TECDOC-1910, Vienna (2020)

[12] Use of a Graded Approach in the Application of the Management System Requirements for Facilities and Activities. IAEA-TECDOC-1740, Vienna (2014)

[13] Use of a graded approach in the application of the safety requirements for research reactors. IAEA Safety Standards Series No. SSG-22, Vienna (2012)

[14] IAEA Safety Glossary: Terminology Used in Nuclear Safety and Radiation Protection, 2018 Edition, IAEA, Vienna (2019).

[15] Fundamental Safety Principles, IAEA Safety Standards Series No. SF, IAEA, Vienna (2006).

[16] Safety of Research Reactors, IAEA Specific Safety Requirements No. SSR-3, IAEA, Vienna (2016).

[17] Maintenance, Periodic Testing and Inspection of Research Reactors, IAEA Safety Standards Series Safety Guide No. NS-G-4.2, IAEA, Vienna (2006).

[18] Rommert Dekker, Applications of maintenance optimization models: a review and analysis, Reliability Engineering and System Safety 51 (1996) 229-240

[19] GUSTAV FREDRIKSSON and HANNA LARSSON, An analysis of maintenance strategies and development of a model for strategy formulation - A case study, MSc. CHALMERS UNIVERSITY OF TECHNOLOGY, Göteborg, Sweden, 2012
[20] John D. Campbell and James V. Reyes-Picknel, Uptime: Strategies for Excellence in Maintenance Management, Third Edition, CRC press by Taylor and Francis group, 2016

[21] THABANI MHLONGO, APPLICATION OF THE PHYSICAL ASSET MANAGEMENT IN THE CITY OF CAPE TOWN WATER SERVICES, MSc. Stellenbosch University, 2009

[22] John D. Campbell, Reliability handbook: from downtime to uptime-in no time, plant engineering and maintenance, volume 23, issue 6 December 1999

[23] IEEE Recommended Practice for Electric Power Distribution for Industrial Plants, IEEE std 1411993.

[24] IEEE Standard for Preferred Power Supply (PPS) for Nuclear Power Generating Stations, IEEE Std 765-1995

[25] Defence in Depth of Electrical Systems, CSNI TECHNICAL OPINION PAPERS No. 16, NEA No. 7070, (C) OECD 2013

[26] Design of Electrical Power Systems for Nuclear Power Plants, IAEA Specific Safety Guide SSG-34, 2016

[27] IEEE Guide for Maintenance, Operation, and Safety of Industrial and Commercial Power Systems, IEEE Std 902-1998. 